\title{
ФОРМИРОВАНИЕ ПРОФЕССИОНАЛЬНЫХ КОМПЕТЕНЦИЙ БУДУЩИХ УЧИТЕЛЕЙ НАЧАЛЬНЫХ КЛАССОВ ЗА ПЕРИОД ПЕДАГОГИЧЕСКОЙ ПРАКТИКИ
}

\section{FORMATION OF PROFESSIONAL COMPETENCIES FUTURE PRIMARY SCHOOL TEACHERS DURING THE PERIOD OF TEACHING PRACTICE}

\section{F. Efendiyeva}

Summary: The main task of the pedagogical practice of future primary school teachers is to consolidate and deepen the theoretical knowledge gained in various subjects in higher educational institutions, to use it creatively in educational work carried out during practice, to instill in students the ability to observe and analyze educational work conducted with pupils of grades I-IV, to form the ability to apply modern teaching methods, new pedagogical technologies in the specialty, to teach students to conduct educational work referring to knowledge of psychology, pedagogy, methodology and taking into account the age and individual characteristics of students. The article comments on these issues.

Keywords: teaching practice, education, teacher, assessment, curriculum.

\author{
Эфендиева Фидан Эмин гызы \\ Преподаватель, Бакинский славянский университет \\ fida84@bk.ru
}

Аннотация: Основная задача педагогической практики будущих учителей начальных классов - закрепить и углубить теоретические знания, полученные по разным предметам в высших учебных заведениях, творчески использовать их в учебно-воспитательной работе, проводимой во время практики, привить студентам умения наблюдать и анализировать учебно-воспитательную работу, проводимую с учениками I-IV классов, сформировать умение применять современные методы обучения, новые педагогические технологии по специальности, научить студентов вести учебно-воспитательную работу ссылаясь на знания по психологии, педагогики, методики и с учетом возрастных и индивидуальных особенностей учащихся. В статье комментируются эти вопросы.

Ключевые слова: педагогическая практика, образование, учитель, оценивание, учебная программа.

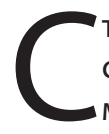

туденческая практика - это система со сложной структурой. Содержание, средства, методы и формы практики разнонаправлены в зависимости от профиля высшего учебного заведения и подготовки специалистов. В научно-педагогической и методической литературе рассматриваются две формы практики (производственная практика и педагогическая практика), проводимая в вузе [3, с.372-373]. Практика, наряду с тем, что является структурным элементом процесса высшего образования, также считается решающим этапом в подготовке специалистов.

С этой точки зрения, педагогическая практика имеет важное значение при подготовке будущих учителей начальных классов к педагогической деятельности. Способность студентов применять теоретические знания по различным предметам («Азербайджанский язык», «Математика», «Познание мира», «Музыка», «Изобразительное искусство», «Технология», «Физическое воспитание») и формирование качеств, свойственных учителю (справедливость, гуманизм, объективность и др.) создание необходимых профессиональных компетенций для реализации профессиональных функций осуществляется посредством педагогической практики. В этом процессе будущие учителя начальных классов приобретают необходимые умения и навыки (компетенции), связанные с профессиональной деятельностью. За время педагогической практики, подготовка будущих учителей начальных классов к педагогической деятельности зависит от того, как организована педагогическая практика и насколько ответственно к ней относятся обучающиеся.

Основная цель педагогической практики будущих учителей начальных классов, заключается в формировании у студента-практиканта профессиональных навыков, присущих учителю, и привитие основных функций педагогической деятельности.

В ходе педагогической практики студенты учатся обеспечивать единство учебно-воспитательного процесса с целью воспитания учеников в соответствии с современными требованиями, входят в круг реальных проблем профессиональной деятельности педагогавоспитателя, знакомятся с основным содержанием и объемом его работы. В связи с этим в период педагогической практики студенты проводят учебно-воспитательную работу по следующим направлениям: психолого-педагогическое, изучение отдельных учащихся и коллектива, проектирование учебной работы, организация открытых уроков, внеклассная деятельность, работа с родителями, классными руководителями, школьными психологами и др. 
В целом основные направления этой работы можно определить так:

1. чему учиться?

2. учебно-воспитательная работа по предмету;

3. ознакомление с учебно-воспитательной работой школы;

4. выполнять функции помощника классного руководителя;

5. методическая работа;

6. исследовательская работа.

Основная задача педагогической практики будущих учителей начальных классов - закрепить и углубить теоретические знания, полученные по разным предметам в высших учебных заведениях, творчески использовать их в учебно-воспитательной работе, проводимой во время практики, привить студентам умения наблюдать и анализировать учебно-воспитательную работу, проводимую с учениками I-IV классов, сформировать умение применять современные методы обучения, новые педагогические технологии по специальности, научить студентов вести учебно-воспитательную работу ссылаясь на знания по психологии, педагогики, методики и с учетом возрастных и индивидуальных особенностей учащихся. Каждый из этих умений - необходимая профессиональная компетенция будущего учителя начальных классов. Хотя основа большинства этих компетенций закладывается у будущих учителей начальных классов в процессе обучения в вузе, она полностью формируется и завершается в период педагогической практики.

Будущие учителя начальных классов, проходившие педагогическую практику, на 14 недель становятся членами педагогического коллектива школы. В этот период они соблюдают правила школьной дисциплины, руководят учениками по единым требованиям, адаптируются к единому плану работы, школьным традициям и подчиняются трудовой дисциплине. В качестве члена коллектива они изучают и обобщают опыт работы передовых учителей. Отношения студентов с учителями строятся на основе взаимоуважения, взаимопонимания, творческом обсуждении педагогических проблем, что, наряду с формированием у них высоких моральных качеств, создают также и профессиональную компетентность, высокий творческий настрой.

Эффективное осуществление педагогической практики, формирование необходимых профессиональных компетенций у будущих учителей начальных классов зависит от учета следующих требований:

- понимание того, что подготовка будущих учителей начальных классов является деятельностью с более практической направленностью;

- осознание того, что педагогическая практика служит не только формированию будущего учителя начальных классов как специалиста, который бу- дет преподавать в I-IV классах, но и как самостоятельной и творчески мыслящей личности, способной определять и решать собственные проблемы, обладающей педагогическим мастерством, исследовательскими и коммуникативными компетенциями.

В функциональной карте педагогической профессии рекомендуется обратить внимание на учебную, образовательную, развивающую деятельность учителя и применение образовательного стандарта, установленного Азербайджанской Республикой для начальных классов общеобразовательных школ. По этой причине формирование трудовой деятельности невозможно без привлечения будущих учителей к практической деятельности (педагогической практике) в государственных и частных общеобразовательных школах.

В период педагогической практики, наряду с общепрофессиональными компетенциям будущих учителей начальных классов особое внимание следует уделять также специфическим профессиональным компетенциям. По этой причине следует заранее учитывать следующие проблемы, которые могут возникнуть при проведении педагогической практики:

1. уделять особое внимание выбору места (школ) (инновационная деятельность школы, плотность учеников, количество начальных классов, количество смен, наличие дополнительных кабинетов для студентов-практикантов и др.);

2. места проведения практики (школы) часто работают изолированно (студент-практикант работает не с руководством школы, педагогическим коллективом, психологом, библиотекарем, школьным врачом, а лишь с закрепленным за ним классом, не создавая условий для обмена опытом с коллегами и учителями);

3. слабая подготовка к социальным аспектам обучения (недостаточная вовлеченность студентовпрактикантов в управление школой, сотрудничество с родителями);

4. недостаточность у учителя класса возможности обдумать и обосновать действия, которые он может посоветовать студенту (студент-практикант должен иметь возможность подумать над собственной практикой и практикой товарищей, учитель класса должен помочь студенту-практиканту найти и проверить на опыте свои собственные уникальные методы обучения).

В период педагогической практики, будущие учителя начальных классов для усвоения особых профессиональных компетенций, должны учитывать следующее:

- учет своеобразия социального положения первоклассника, в связи с превращением учебы в ведущую деятельность в отличие от игры, изменением 
образа жизни, появлением новых обязанностей, нового отношения к окружающим (учитель, одноклассник, директор школы и т. д.);

- обеспечение развития у учащихся начальных классов учебных навыков до уровня, требуемого ступенью начального образования;

- обучить учеников начальных классов правилам обращения к учителю, директору школы, школьному психологу, директору библиотеки, учителюпрактиканту;

- при оценивании успеваемости и учебных достижений учащихся начальных классов, учет особенностей их индивидуального психологического развития.

Учебным планом по специальности «Учитель начальных классов» (050118), утвержденным в 2009 году, для будущих учителей начальных классов предусматривалось 18 недель (36 кредитов) педагогической практики. В инновационных школах города Баку студенты провели 4 недели (8 кредитов) во втором учебном году, 9 недель (18 кредитов) в третьем учебном году и 5 недель (10 кредитов) в четвертом учебном году [2, с.86]. Во время практики студенты наряду с уроками по родному языку, математике, познанию мира, музыке, изобразительному искусству, технологии и физическому воспитанию, также проводили проверочные уроки по английскому языку. Включение предмета «Английский язык» в проверочные уроки было связано с желанием учителей начальных классов преподавать английский язык в своих классах в будущем.

Для этой цели в учебном плане предусмотрена 360-часовая нагрузка. За IV годичный учебный год невозможно было подготовить учителя английского языка с учебной нагрузкой в 360 часов.

Согласно «Положению о проведении практики студентов высших (средних) специальных учебных заведений по специальности» постановлением Кабинета Министров Азербайджанской Республики от 19 сентября 2008 года № 221, учебная нагрузка на одного студента, назначенными руководителями из высших (средних) учебных заведений и общеобразовательных школ на педагогическую практику составила 56 часов. Эти часы были разделены между руководителями практики следующим образом:

- руководителю по педагогике из образовательного учреждения - 4 часа, руководителю по психологии - 2 часа, методисту по специальности - 31 час.

-директору или заместителю директора по учебной работе общеобразовательной школы, где проводится практика -2 часа, учителю-предметнику- 16 часов, и 1 час классному руководителю. В учебном плане, утвержден- ном по специальности «Учитель начальных классов» в 2015 году, продолжительность педагогической практики сокращена с 18 до 14 недель, а проверочные уроки по предметам «Информатика» и «Иностранный язык» («Английский язык») исключены из плана. Часы, предусмотренные для «Иностранного языка» («Английский язык») были отданы «Родному языку» и «Математике».

Учебным планом по специальности «Учитель начальных классов» (050118), утвержденным в 2009 году, для будущих учителей начальных классов предусматривалось 18 недель (36 кредитов) педагогической практики. В инновационных школах города Баку студенты провели 4 недели (8 кредитов) во втором учебном году, 9 недель (18 кредитов) в третьем учебном году и 5 недель (10 кредитов) в четвертом учебном году [2, с.86]. Во время практики студенты наряду с уроками по родному языку, математике, познанию мира, музыке, изобразительному искусству, технологии и физическому воспитанию, также проводили проверочные уроки по английскому языку. Включение предмета «Английский язык» в проверочные уроки было связано с желанием учителей начальных классов преподавать английский язык в своих классах в будущем.

Для этой цели в учебном плане предусмотрена 360-часовая нагрузка. За IV годичный учебный год невозможно было подготовить учителя английского языка с учебной нагрузкой в 360 часов.

Согласно «Положению о проведении практики студентов высших (средних) специальных учебных заведений по специальности» постановлением Кабинета Министров Азербайджанской Республики от 19 сентября 2008 года № 221, учебная нагрузка на одного студента, назначенными руководителями из высших (средних) учебных заведений и общеобразовательных школ на педагогическую практику составила 56 часов. Эти часы были разделены между руководителями практики следующим образом:

- руководителю по педагогике из образовательного учреждения - 4 часа, руководителю по психологии - 2 часа, методисту по специальности - 31 час.

- директору или заместителю директора по учебной работе общеобразовательной школы, где проводится практика -2 часа, учителю-предметнику- 16 часов, и 1 час классному руководителю. В учебном плане, утвержденном по специальности «Учитель начальных классов» в 2015 году, продолжительность педагогической практики сокращена с 18 до 14 недель, а проверочные уроки по предметам «Информатика» и «Иностранный язык» («Английский язык») исключены из плана. Часы, предусмотренные для «Иностранного языка» («Английский язык») были отданы «Родному языку» и «Математике». 
Утвержденная в 2020 году Образовательная программа не внесла существенных изменений в сроки педагогической практики. Хотя серьезной темой для обсуждения стал вопрос о сокращении периода обучения на 3 года в вузах, осуществляющих долгое время подготовку педагогических кадров, и прохождение студентами 1 годичной педагогической интернатуры [1, с.23].

Педагогическая практика как для вузов (педагог, психолог, методист, будущие учителя), так и для общеобразовательной школы (классный руководитель, директор школы, заместитель директора по учебно-воспитательной работе, психолог и др.) для каждого из участников данного процесса является учебной средой, местом для развивающего обучения. Эффективная организация педагогической практики, направлена на повышение результатов деятельности всех участников учебного процесса. За время педагогической практики будущие учителя, проходящие начальную педагогическую подготовку, и сотрудники учебно-воспитательного заведения школы, где организована практика, проводят совместные исследования в различных условиях обучения. Педагогическая практика гарантирует, что будущие учителя начальных классов войдут в мир как независимой, так и коллективной практики. Поэтому при разработке программы педагогической практики учитываются профессиональные компетенции будущих учителей начальных классов, а сотрудники общеобразовательной школы для развития необходимых профессиональных компетенций создают различные возможности для студентов, прошедших начальную педагогическую подготовку. Педагогическая практика и высшее образование тесно интегрируют, что позволяет будущим учителям получить как профессиональные знания, так и практический опыт по специальности. Студенты, проходящие начальную педагогическую подготовку в различной учебной среде (разные школы, разные учителя, разные подходы) практикуются по специальности. Это позволяет обсуждать и критически анализировать не только опыт профессии, но и различия между опытом студентов и отдельных учителей.

Программа педагогической практики призвана обеспечить, чтобы будущие учителя начальных классов, прошедшие начальную педагогическую подготовку, постепенно брали на себя педагогические обязанности и обрели педагогическую независимость. Это позволяет будущим учителям класса постепенно переходить от контролируемой среды (среды высшего образования) к независимой и в то же время коллективной среде [4, с.1].

Эффективность и продуктивность педагогической практики зависит от совместной деятельности общеобразовательной школы и высшего учебного заведения, готовящего будущих учителей начальных классов. Следовательно, содержание, технология, реализация, завершение, оценивание программы педагогической практики подготавливаются в рамках взаимного сотрудничества сотрудников обоих учебных заведений. Это сотрудничество осуществляется посредством различных комиссий, официальных соглашений, рабочих групп и совместных встреч.

Перед началом педагогической практики, с участием представителей высших и базовых учебных заведений, участвующих в процессе практики проводится обучающая, а по окончании - итоговая конференция. Результаты обучения, связанные с практикой, должны обсуждаться на начальной конференции, посвященной практике, с участием педагогов, психологов, методистов, учителей класса и будущих учителей начальных классов, и должны быть созданы благоприятные условия для реализации каждого результата (компетенции). Такое условие, чтобы будущие учителя начальных классов могли бы войти в учебную жизнь учеников младшего школьного возраста. Будущий учитель начальных классов, успешно прошедший педагогическую практику, должен обладать следующими компетенциями:

- уметь связать все преподаваемые предметы с учебным процессом;

- продемонстрировать усвоения методики преподавания предмета;

- продемонстрировать способность создавать интеграцию (внутрипредметную и межпредметную) в учебном процессе;

- применять инновации в процессе преподавания знаний по предмету;

- применять педагогические технологии в преподавании предмета;

- продемонстрировать, понимание образа мышления и проявления чувства детей;

- уметь спроектировать урок;

- продемонстрировать, что учитываются потребности и индивидуальные особенности учащихся при планировании;

- продемонстрировать способность выбирать подходящие методы обучения, учебные материалы и ресурсы, приобретать навыки для подготовки учебных материалов и средств;

- продемонстрировать умение организовать педагогический процесс, связать урок с повседневной жизнью и опытом, соблюдать распределение времени, обладать умением проводить урок согласно плану;

- уметь сотрудничать со студентами;

- уметь индивидуализировать обучение с учетом особых потребностей учащихся в процессе обучения;

- уметь правильно разрешать спорные и противоречивые процессы в классе;

- уметь создавать активную и демократичную обучающую среду; 
- соблюдать правила школы и класса во время практики, побуждать учеников соблюдать эти правила;

- относиться ко всем ученикам справедливо и с уважением, формировать у них чувство доверия и уважения;

- уметь общаться с учениками;

- уметь разъяснить цель урока, дать четкое и исчерпывающее объяснение вопросов;

- продемонстрировать умение задавать правильно построенные вопросы для развития критического мышления учащегося;

- проявлять искреннее отношение к ученикам, внимательно выслушивая их вопросы и предложения;

- умеет определять соответствующие индикаторы, выбирать и разрабатывать соответствующие средства оценивания;

- умеет объективно оценивать подготовку и развитие учеников, анализировать результаты оценивания;

- умеет вносить определенные изменения в процесс обучения на основе анализа результатов оценивания;

- продемонстрировать умение сотрудничать с будущими коллегами, школьным коллективом и родителями;

- участвовать в различных школьных мероприятиях, выражает свое мнение по обсуждаемым вопросам, вносит соответствующие предложения и рекомендации;

- уметь продемонстрировать ценности и поведение, которые он ожидает от своих учеников;

- демонстрировать способность повышать качество учебного процесса, анализируя свою деятельность, наблюдая и консультируя коллег;

- демонстрировать способность улучшать процесс преподавания и обучения путем проведения небольших исследований;

- продемонстрировать, что знает выдающихся ученых, государственных и общественных деятелей и может эффективно использовать эти знания в образовательном процессе;

- продемонстрировать общую и педагогическую культуру.

Выше перечисленное, можно обобщить как организационные, обучающие, коммуникативные, перцептивные, исследовательские, сотруднические и другие компетенции будущих учителей начальных классов.

Педагогическая практика оценивается как естественный составной элемент знакомства студентов со школьной жизнью. Будущие учителя начальных классов, проходящие практику в школе, оцениваются совместно педагогом, методистом, психологом и учителем класса, ведущим педагогическую практику, на предмет их спо- собности достигать результаты обучения и выполнять процессы, описанные ниже:

- вести себя в соответствии с профессией учителя;

- понимать учеников;

- организовать учебный процесс;

- управлять классом;

- эффективно использовать учебные ресурсы;

- правильное использование современных методов обучения;

- правильно спроектировать проверочный урок;

- оценивать учеников, анализировать выполняемые ими задания;

- обогатить школьную жизнь внеклассными мероприятиями;

- формировать у учащихся нравственные и духовные качества путем ведения воспитательных бесед;

- самооценивание.

В Бакинском Славянском Университете педагогической практикой будущих учителей начальных классов руководит кафедра Начального образования. Перед практикой преподаватели педагогики раздают учителям начальных классов специальные образцы анкет. Согласно вышеупомянутым пунктам, в анкете спрашивается, обладает ли студент, закрепленный к тому классу, умениями работать учителем. При проведении итогового оценивания, педагог, методист и психолог учитывают мнение учителя класса о профессиональных компетенциях студента. Все это отражается в Характеристике студента.

На наш взгляд, оценивание студентов должно быть естественным и реальным, и к ним следует относиться как к учителям. Каждый студент-практикант должен продемонстрировать, что он овладел профессиональными компетенциями, необходимыми учителю. Опыт показывает, что результаты обучения студентов в вузе иногда не совпадают с их достижениями, полученными в период педагогической практики. Во время педагогической практики есть много студентов, которые отличаются эффективной педагогической деятельностью, общением с учащимися и учителями, которые не могут показать успешные результаты на экзаменационных сессиях. Педагогическая практика - это не только место проб и ошибок, но и первая лаборатория педагогической деятельности. Студент, во время практики, общаясь с учителем класса должен пользоваться его советами. Учитель класса должен обсудить деятельность и достижения студентов с преподавателями высших учебных заведений. В некоторых случаях, если заранее чувствуется, что студент потерпит неудачу в этой области, ему могут посоветовать не продолжать курс или сменить профессию. Высшее учебное заведение несет ответственность за выполнение всех процессов, связанных с практикой студентов, за надлежащее выполнение обязанностей учителей класса и школ. Вся эта работа организована при сотрудничестве вузов и школ на договорной основе. Для 
того, чтобы эти функции были реализованы должным образом, было бы лучше разместить соответствующие кафедры высших учебных заведений в школах, где проводится педагогическая практика, или создать их филиалы в школах.

В результате целенаправленной организации педагогической практики, будущие учителя начальных классов обладают следующими умениями:

- умением объединять детей в классе, планировать работу, разделять обязанности, обобщать проделанную работу;

- умением выбрать и подготовить дидактические материалы, наглядные пособия, средства, объяснять дидактические материалы в понятной, ясной, выразительной, убедительной и последовательной форме;

- умением использовать инклюзивные образовательные технологии в процессе обучения, понимать образ мышления детей, видеть их внутренний мир, объективно оценивать их эмоциональное состояние, определять возрастные, индивидуальные, психологические, анатомо-физиологические особенности и учитывать их в учебном процессе;

- умением к целенаправленному общению с учениками, их родителями, способностью повышать эффективность и качество учебного процесса в начальных классах с использованием различных инновационных учебных ресурсов и технологий и т.д.

\section{ЛИТЕРАТУРА}

1. Аббасов А. Педагогическая интернатура. Баку: Мутарджим, 2015, 48 c.

2. Курикулум предмета «Педагогика» по подготовке учителей на ступени бакалавриата высшего образования. (Составители: проф. Ф. Рустамов, доцент Я. Рзаева, доцент Т. Вахабова, доцент Т. Гусейнова, доцент М. Заманова). Баку: Наука и образование, 2014, 92 с.

3. Рустамов Ф., Дадашева Т. Педагогика высшей школы. Баку: Нурлан, 2007, 567 с.

4. Тагиева С. Эффективные пути организации педагогической практики при подготовке студентов вузов к педагогической профессии. Автореферат диссертации на соискание ученой степени доктора философии по педагогике. Ленкорань: Лгу, 2001, 23 с.

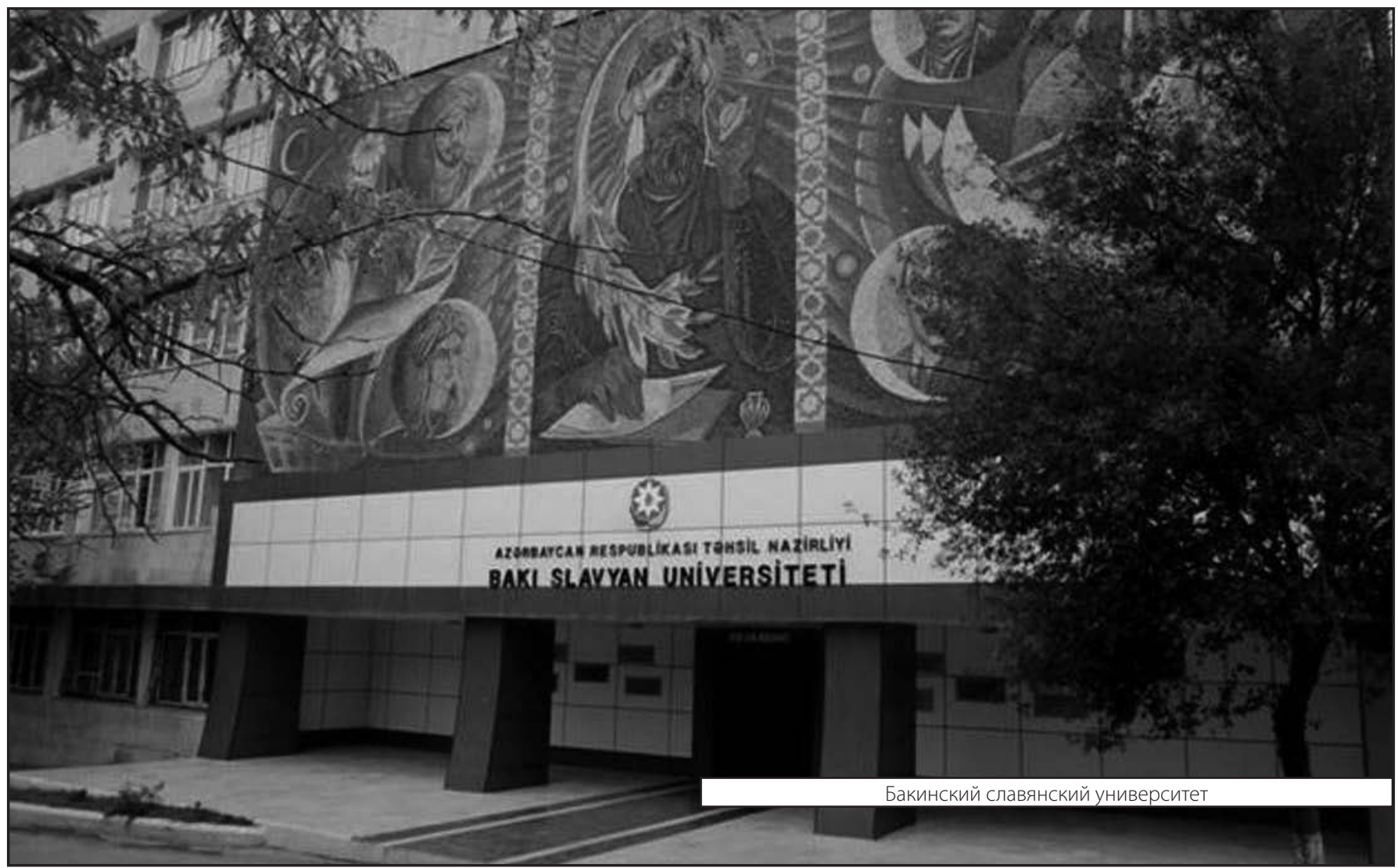

